\title{
The Role of Diverting Stoma After an Ultra-low Anterior Resection for Rectal Cancer
}

\author{
Seok In Seo, Chang Sik Yu, Gwon Sik Kim, Jong Lyul Lee, Yong Sik Yoon, Chan Wook Kim, Seok-Byung \\ Lim, Jin Cheon Kim \\ Department of Colon \& Rectal Surgery, Asan Medical Center, University of Ulsan College of Medicine, Seoul, Korea
}

Purpose: A diverting stoma is known to reduce the consequences of distal anastomotic failure following colorectal surgery. The aim of this study was to evaluate the efficacy of a diverting stoma after an ultra-low anterior resection (uLAR) for rectal cancer.

Methods: Between 2000 and 2007, 836 patients who underwent an uLAR were divided into two groups, depending on the fecal diversion: 246 received fecal diversion, and 590 had no diversion. Patient- and disease-related variables were compared between the two groups.

Results: Thirty-two of the 836 patients (3.8\%) had immediate anastomosis-related complications and required reoperation. Anastomosis leakage comprised $72 \%$ of the complications (23/32). The overall immediate complication rate was significantly lower in patients with a diverting stoma $(0.8 \%, 2 / 246)$ compared to those without a diverting stoma $(5.1 \%$, 30/590; $\mathrm{P}=0.005)$. The fecal diversion group had lower tumor location, lower anastomosis level, and more preoperative chemo-radiation therapy $(\mathrm{P}<0.001)$. In total, $12 \%$ of patients in the diverting stoma group had complications either in making or reversing the stoma $(30 / 246)$.

Conclusion: The diverting stoma decreased the rate of immediate anastomosis-related complications. However, the rate of complications associated with the diverting stoma was non-negligible, so strict criteria should be applied when deciding whether to use a diverting stoma.

Keywords: Rectal neoplasms; Ileostomy; Colorectal surgery

\section{INTRODUCTION}

Following the introduction of circular staplers in the 1970s and the double stapling technique in the 1980s, the low colorectal anastomosis became a common procedure and is now regarded as routine. A stapled anastomosis is safe, effective, and easy to perform. A major advantage of this technique is that it is per-

Received: March 11, 2013• Accepted: April 1, 2013

Correspondence to: Chang Sik Yu, M.D.

Department of Colon \& Rectal Surgery, Asan Medical Center, University of Ulsan Collage of Medicine, 88 Olympic-ro 43-gil, Songpa-gu, Seoul 138-736, Korea

Tel: +82-2-3010-3494, Fax: +82-2-474-9027

E-mail: csyu@amc.seoul.kr

(c) 2013 The Korean Society of Coloproctology

This is an open-access article distributed under the terms of the Creative Commons Attribution NonCommercial License (http://creativecommons.org/licenses/by-nc/3.0) which permits unrestricted noncommercial use, distribution, and reproduction in any medium, provided the original work is properly cited. formed under direct vision without the impediment of pelvic tissue [1-3]. For a routine low anterior resection, a diverting stoma is not typically necessary. However, the risk of complications, such as leakage, a major adverse event [4], stricture, and fecal incontinence, increases in cases involving sphincter-saving surgery for mid to lower rectal cancer due to the lower level of the anastomosis. Furthermore, anastomotic leakage after rectal cancer surgery has been associated with poor survival $[5,6]$.

Risk factors contributing to anastomosis leakage include male gender, malnutrition, preoperative weight loss, cardiovascular disease, steroid use, perioperative blood transfusion, advanced age, obesity, previous irradiation, and a low level of anastomosis [5, 7-12]. It has been argued that a diverting stoma is an effective and safe procedure to prevent anastomosis leakage after sphincter-saving surgery $[4,7,13-17]$. However, it has been reported that a diverting stoma may not prevent postoperative anastomotic leakage [18-20]. Furthermore, systematic reviews have reported that complications related to the closure of a diverting stoma were not neg- 
ligible [21, 22]. Chow et al. [21] reviewed 48 studies evaluating the complications associated with the reversal of a diverting ileostomy and reported a morbidity rate of $17.3 \%$ with a mortality rate of $0.4 \%$. Stoma-related complications included small bowel obstruction $(7.2 \%)$, wound sepsis $(5 \%)$, the need for relaparotomy $(2.5 \%)$, incisional hernia of the stoma site $(1.8 \%)$, leakage $(0-8.3 \%)$, prolonged ileus $(0.8-13.8 \%)$, fistula $(0-8.6 \%)$, bleeding $(0-4 \%)$, and intra-abdominal abscess $(0-1.4 \%)$.

An ultra-low anterior resection (ULAR) is associated with a very low anastomosis level and frequently with preoperative chemoradiation therapy (CRT). These factors often require a diverting stoma to be performed. Therefore, the aims of our study were to assess the complications and the effectiveness of a diverting stoma following an ULAR for rectal cancer.The present study was approved by the Institutional Review Board for Human Research at the University of Ulsan.

\section{METHODS}

\section{Eligibility and enrollment}

Between January 2000 and December 2007, a total of 836 patients underwent an elective and curative ULAR for rectal cancer at Asan Medical Center. The term 'uLAR' is applied if the rectal dissection proceeds below the pelvic floor or the rectum is excised completely. The median follow-up period was 54 months, with a range of 6-146 months. The patients were divided into two groups: 246 underwent an uLAR with fecal diversion and 590 underwent an ULAR without fecal diversion (see below for selection criteria). Diverting stoma-related complications were divided into two categories: stoma creation and stoma reversal. Demographic, preoperative, operative, pathologic, and follow-up data were available from the medical records and a prospectively managed database.

\section{Surgery}

For patients receiving preoperative CRT, which was performed with a total of 40-50.4 Gy with FL (5-fluorouracil + leucovorin) or capecitabin, surgery was performed 5 to 6 weeks after completion of treatment. Eight patients were observed to have symptomatic obstruction during the work-up period and underwent diverting stoma surgery before receiving preoperative CRT and undergoing an uLAR. All operations were performed by colorectal surgeons who had each performed more than 150 mesorectal excisions per year for the previous 5 years. The standard procedure was a total mesorectal excision with autonomic nerve preservation. All patients were anastomosed with a double stapling technique, except for two patients who underwent single stapling and five patients who were hand-sewn. Temporary diverting stomas were created as loop ileostomies in patients with more than one of the following: a very low anastomotic level under considerable tension, poor blood supply, positive air leak test result, preoperative CRT, or severe comorbidity. An ileostomy take down was performed via a functional end-to-end anastomosis by using either a linear stapler or a hand-sewn technique.

\section{Follow-up}

Colon studies using water-soluble contrast media and digital rectal examination were performed 3 to 4 months after the uLAR with diverting stoma or approximately 1 month after completion of adjuvant therapy. If the test results were normal and the patient had no evidence of recurrence, closure of the diverting stoma was performed. Conversely, if a leak or stenosis was observed, closure was postponed until the leak had healed or the stenosis had been resolved with one or more dilations.

Anastomotic leakage was defined as peritonitis caused by leakage, pelvic abscess, or discharge of feces from the pelvic drain at any postoperative stage. Immediate anastomosis-related complications included leakage, pelvic sepsis, fistula, anastomosis bleeding, or bowel ischemia within a month from the uLAR.

Stoma-related complications were collected from the medical records and a prospectively managed database. Ileus was considered as either prolonged postoperative ileus or delayed ileus. Prolonged postoperative ileus was specified as a delay of 7 days in passing gas. A prolapsed stoma was defined as the need to manually or surgically reduce the bowel. Patients who had radiologic herniation and complained of discomfort at the stoma site were considered to have an incisional hernia of the stoma repair site.

\section{Statistical analysis}

Categorised variables were analysed with the chi-squared $\left(\chi^{2}\right)$ test. Continuous variables were analysed with the Student's t-test. All numbers are expressed as means \pm standard deviations. A P-value of $<0.05$ was considered statistically significant. All statistical calculations were performed with IBM SPSS ver. 19.0 (IBM Co., Armonk, NY, USA).

\section{RESULTS}

\section{Differences in patient characteristics in the stoma diversion group}

The proportion of men, rate of permanent stoma formation, and pathologic status did not differ between the two groups. However, patients undergoing a diverting stoma were associated with a lower anastomosis level, lower tumor location, higher perioperative and preoperative CRT rates, and lower postoperative CRT rates $(\mathrm{P}<$ 0.001). In addition, the median age and rate of immediate anastomosis-related complications were significantly lower for divertingstoma patients $(\mathrm{P}<0.008$ and $\mathrm{P}<0.005$, respectively) (Table 1 ).

The fraction of patients who received preoperative CRT was $36 \%$ (299/836). Further, the mean age of the preoperative CRT group was younger than that of the nonpreoperative CRT group (55 years and 58 years, $\mathrm{P}<0.001)$. Approximately half $(53 \%$, 157/299) of the patients who received preoperative CRT underwent a diverting stoma. Patients with diversion had lower pelvic 
sepsis rates than those without it, but the difference was not significant $(1.3 \%$ vs. $4.9 \%, \mathrm{P}=0.091)$.

\section{Diversion timing and permanent stoma}

A total of 275 patients received a diverting ileostomy, followed by a second procedure for stoma closure. Prechronous or synchro-

Table 1. Patient demographics and perioperative details

\begin{tabular}{|c|c|c|c|}
\hline \multirow{2}{*}{ Characteristic } & \multicolumn{2}{|c|}{ uLAR for rectal cancer $(n=836)$} & \multirow{2}{*}{ P-value } \\
\hline & Diversion $(n=246)$ & No diversion $(n=590)$ & \\
\hline Age (yr) & $56 \pm 11$ & $58 \pm 11$ & $0.008^{c}$ \\
\hline Locations from AV (cm) & $4.6 \pm 1.4$ & $5.6 \pm 1.3$ & $<0.001^{\circ}$ \\
\hline Anastomosis level (cm) & $2.0 \pm 0.9$ & $3.1 \pm 0.9$ & $<0.001^{\mathrm{c}}$ \\
\hline Male sex & $164(66.7)$ & $355(60.2)$ & 0.085 \\
\hline Perioperative CRT & & & $<0.001^{\circ}$ \\
\hline Yes & $206(83.7)$ & $357(60.5)$ & \\
\hline No & $40(16.3)$ & $233(39.5)$ & \\
\hline Preoperative CRT & & & $<0.001^{\circ}$ \\
\hline Yes & $157(63.8)$ & $142(24.1)$ & \\
\hline No & 89 (36.2) & $448(75.9)$ & \\
\hline Postoperative CRT & & & $<0.001^{\circ}$ \\
\hline Yes & 49 (19.9) & $215(36.4)$ & \\
\hline No & $197(80.1)$ & $375(63.6)$ & \\
\hline $\begin{array}{l}\text { Immediate anastomosis- } \\
\text { related complication }\end{array}$ & & & $0.005^{\circ}$ \\
\hline Yes & $2(0.8)^{a}$ & $30(5.1)^{b}$ & \\
\hline No & $244(81.3)$ & $560(94.9)$ & \\
\hline Permanent stoma & & & 0.300 \\
\hline Yes & $9(3.7)$ & $32(5.4)$ & \\
\hline No & $237(96.3)$ & $558(94.6)$ & \\
\hline T stage & & & 0.182 \\
\hline$<3$ & $86(34.9)$ & $237(40.2)$ & \\
\hline$\geq 3$ & $160(65.1)$ & $353(59.8)$ & \\
\hline $\mathrm{N}$ stage & & & 1.000 \\
\hline Negative & $147(59.8)$ & $350(59.4)$ & \\
\hline Positive & 99 (40.2) & $240(40.6)$ & \\
\hline M stage & & & 0.889 \\
\hline Negative & 235 (95.5) & $556(94.2)$ & \\
\hline Positive & $11(4.5)$ & $34(5.8)$ & \\
\hline $\mathrm{p}$-stage & & & 0.807 \\
\hline I, II & 107 (43.5) & $250(42.3)$ & \\
\hline III, IV & $139(56.5)$ & $340(57.7)$ & \\
\hline
\end{tabular}

Values are presented as mean \pm standard deviation or number (\%).

uLAR, ultra-low anterior resection; AV, anal verge; CRT, chemo-radiation therapy; PCRT, preoperative CRT.

${ }^{a}$ Cause of two permanent stomas was anastomotic leakage (ileostomy 1 , abdomino perineal resection [APR] 1). ${ }^{b} \mathrm{~N}$ o. of patients who had a permanent stoma after anastomotic leakage was only five (ileostomy 1 , APR 4). ${ }^{\mathrm{C}} \mathrm{P}<0.05$. nous diversion was performed in 246 patients. Only one patient did not undergo a diverting-stoma reversal. A further 30 patients that initially did not receive a diverting stoma underwent the procedure following anastomosis-related complications, and 29 out of the 30 patients (97\%) received a stoma reversal (Fig. 1). The durations to diverting stoma reversal were similar, irrespective of whether the patient received the diverting stoma as part of the initial anastomosis or due to anastomosis-related complications ( $7 \pm 3$ months vs. $7 \pm 8$ months, $\mathrm{P}=0.573$ ).

\section{Immediate anastomosis-related complications}

Only $3 \%$ of the patients (23/836) suffered symptomatic anastomotic leakage, and $0.8 \%$ of the patients $(2 / 246)$ with a diverting stoma experienced immediate anastomosis-related complications. However, $5.1 \%$ of the patients (30/590) without a diverting stoma suffered immediate anastomosis-related complications. Anastomosis leakage comprised 73\% (22/30) of the complications. Patients with a diverting stoma suffered lower symptomatic anastomosis leakage rates than those without a diverting stoma $(0.4 \%$ vs. $3.7 \%, \mathrm{P}=0.005$ ) (Table 2).

\section{Diverting stoma-related complications}

The overall rate of complications following either the creation or the closure of a diverting stoma was $12 \%(30 / 246)$. The overall

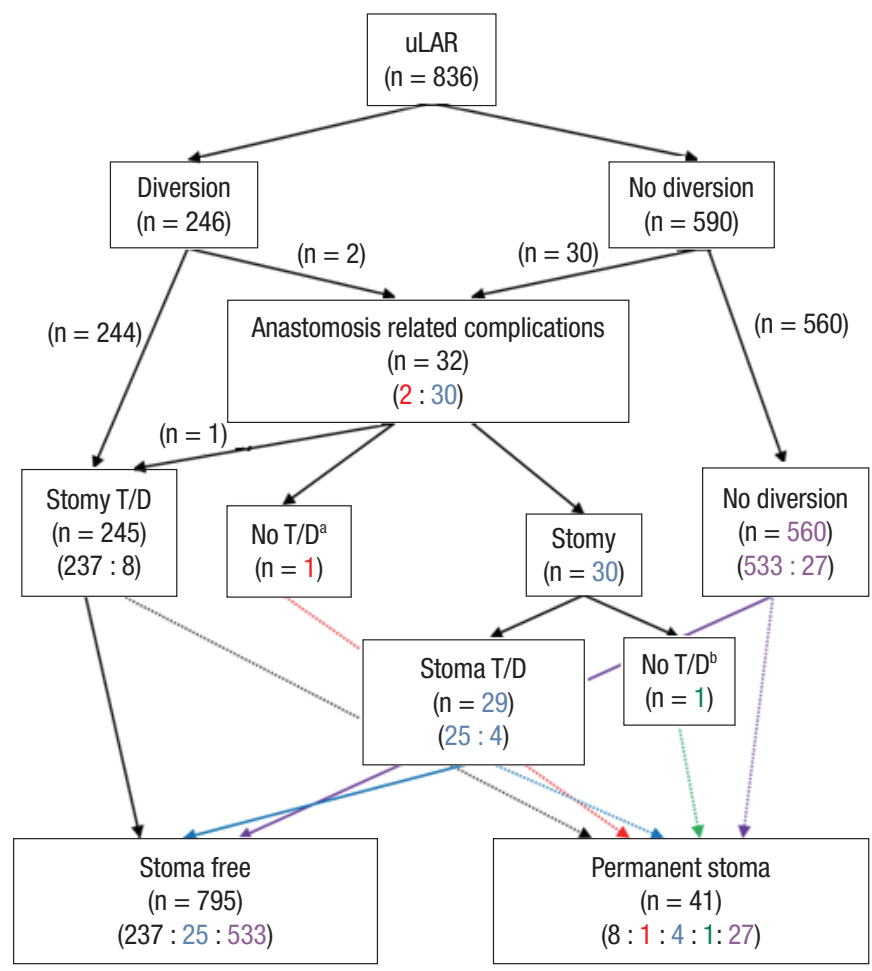

Fig. 1. Evolutional changes in stoma status. uLAR, ultra-low anterior

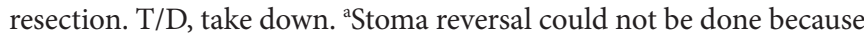
of tumor recurrence. ${ }^{\mathrm{b}}$ Anastomosis leakage was continued. 
Table 2. Types of immediate anastomosis-related complications

\begin{tabular}{lcc}
\hline Type & $\begin{array}{c}\text { Diversion } \\
(\mathrm{n}=246)\end{array}$ & $\begin{array}{c}\text { No diversion } \\
(\mathrm{n}=590)\end{array}$ \\
\hline Symptomatic anastomosis leakage & $1(0.4)$ & $22(3.7)$ \\
Pelvic abscess & - & $3(0.5)$ \\
Rectovaginal fistula & - & $3(0.5)$ \\
Rectourethral fistula & - & $1(0.2)$ \\
Anastomosis bleeding & - & $1(0.2)$ \\
Proximal bowel ischemia & $1(0.4)$ & - \\
Total & $2(0.8)$ & $30(5.1)$ \\
\hline
\end{tabular}

Values are presented as number (\%).

rate of complications associated with a diverting stoma that required surgery was 5.3\% (13/246). After undergoing a diverting stoma, 13 out of 246 patients (5.3\%) suffered stoma-related complications. Out of these, a third of the patients required surgical correction (Table 3 ). The complication rate associated with reversal of the diverting stoma was $6.9 \%(17 / 245)$. The complication rate requiring surgery was also about one third (6/17). The main reason for surgical correction was postoperative ileus (Table 4). There were no mortalities.

\section{DISCUSSION}

The total mesorectal excision (TME) technique and preoperative CRT were standard treatments for mid to low rectal cancer. However, they have been associated with an increased risk of symptomatic anastomotic leakage $[4,23]$. Symptomatic anastomotic leakage can be a catastrophic complication after sphincter-saving surgery for rectal cancer, with an incidence that has been reported as ranging from $1 \%$ to $24 \%[5,7,15,16,19,24,25]$. Mortality associated with anastomotic leakage has been reported as ranging from $2.1 \%$ to $22 \%$ [7, 16, 19].Furthermore, anastomosis leakage has been reported to be an independent prognostic factor for local recurrence [26, 27]. Jung et al. [5] reported that anastomosis leakage had significantly poorer long-term survival because the adjuvant chemotherapy was delayed or abandoned. Long-term functional outcome is also impaired by anastomotic leakage that reduces neorectal reservoir functions, owing to failure of healing by first intention with granulation tissue formation and consequent fibrosis $[28,29]$. In our study, only $3 \%$ of the patients (23/836) suffered symptomatic anastomotic leakage, and there were no mortalities. Our leakage rate was very low compared to other studies. Only one of the 246 patients who underwent an ULAR with a diverting stoma could not undergo diverting stoma reversal because of tumor recurrence. These results may be attributed to robust selection criteria that considered high-risk patients and the appropriate use of diverting stoma.

We found that the diverting stoma group had a lower anastomosis level and a higher rate of preoperative CRT. These results may
Table 3. Complications associated with creating the ileostomy $(\mathrm{n}=246)$

\begin{tabular}{lccc}
\hline Complication & $\begin{array}{c}\text { Required } \\
\text { surgery }(n=7)\end{array}$ & $\begin{array}{c}\text { Conservative } \\
\text { treatment }(n=6)\end{array}$ & Total \\
\hline Prolapse & 2 & 3 & $5(2.0)$ \\
lleus & 3 & 2 & $5(2.0)$ \\
Bowel perforation & 2 & - & $2(0.8)$ \\
High output ileostomy $^{\mathrm{a}}$ & - & 1 & $1(0.4)$ \\
\hline
\end{tabular}

Values are presented as number (\%).

aNeeded fluid resuscitation in the hospital.

Table 4. Complications associated with reversal of the diverting stoma $(\mathrm{n}=245)$

\begin{tabular}{lccr}
\hline Complication & $\begin{array}{c}\text { Required } \\
\text { surgery }(\mathrm{n}=6)\end{array}$ & $\begin{array}{c}\text { Conservative } \\
\text { treatment }(\mathrm{n}=11)\end{array}$ & \multicolumn{1}{c}{ Total } \\
\hline Incisional hernia & 1 & 2 & $3(1.2)$ \\
Ileus & 4 & 9 & $13(5.3)$ \\
Bleeding & 1 & - & $1(0.4)$ \\
\hline
\end{tabular}

Values are presented as number (\%).

be attributed to our selection criteria. We performed a diverting stoma in cases with more than one of these conditions: a very low anastomotic level under considerable tension, poor blood supply, positive air leak test result, preoperative CRT, and severe comorbidity. Further, the mean age of the diversion group was younger than that of the nondiversion group. This may be due to the more frequent use of preoperative CRT in young patients. Furthermore, the diverting stoma group suffered fewer immediate anastomosisrelated complications. We hypothesise that a diverting stoma may be a highly effective modality to prevent clinical anastomotic leakage after an uLAR for rectal cancer, although the younger age of the patients with a diverting stoma may be a factor in its comparative success.

A recent study showed that $19 \%$ of patients obtained a permanent stoma after a low anterior resection for rectal cancer, and $56 \%$ of the patients with a permanent stoma had previous symptomatic anastomotic leakage [30]. In this study, the rate of permanent stomas was $5 \%(41 / 836)$, and only $15 \%$ of the patients $(6 / 41)$ with a permanent stoma suffered previous symptomatic anastomotic leakage. The main cause of a permanent stoma was recurrence. Only one of 246 patients with a diverting stoma suffered symptomatic anastomotic leakage. However, $3.7 \%$ of the patients (22/590) who underwent an uLAR without a diverting stoma had symptomatic anastomosis leakage $(\mathrm{P}=0.005)$.

Our results are in agreement with previous studies on a diverting stoma and its relation to a reduction in anastomosis-related leakage. However, it must be recognized that a diverting stoma requires the patient to undergo two surgeries. Furthermore, some studies have reported considerable stoma-related complication rates $[21,22,31]$. In a recent review of 48 studies, including 6,107 cases, the reported overall morbidity following closure of a divert- 
ing stoma was found to be $17.3 \%$, with a mortality rate of $0.4 \%$. The two major postoperative complications were small bowel obstruction and wound sepsis [21]. Our overall rate for stoma-related complications was $12 \%(30 / 246)$, and $5.3 \%$ of the patients $(13 / 246)$ required surgery. There were no mortalities. We found that the rate of stoma-related complications was non-negligible and that the rate of complications for stoma creation and closure was quite similar to those in other studies. The most common complication after stoma reversal was ileus at 5.3\% (13/245). In one systemic review, $7.2 \%$ of the patients $(339 / 4,735)$ suffered from small bowel obstruction following ileostomy closure, and a third of those patients (107/339) required a relaparotomy [21]. Our study showed similar data as $31 \%$ of the patients (4/9) with ileus after reversal of the diverting stoma required reoperation. Furthermore, three cases of incisional hernia and one case of anastomotic bleeding were identified following stoma reversal. Therefore, reversal of a loop ileostomy requires careful attention to detail to prevent postoperative ileus. We recommend lysis of all adhesions under direct vision and careful reanastomosis, taking care to prevent anastomosis stricture and bleeding.

Complication rates following loop ileostomy construction have been reported as ranging from $4 \%$ to $45 \%$, and reoperation rates have been reported to be between $1 \%$ and $6 \%$ [32-35]. Excluding ileus that was resolved within 3 days and minor wound problems, we found that, similar to other studies, $5.3 \%$ of the patients with a diverting stoma (13/246) suffered complications, and the reoperation rate was $2.8 \%(7 / 246)$. This retrospectively designed study has a limitation, possible selection bias, because some patients underwent a diverting stoma based on the final decision of the surgeon, even though some specific conditions for diversion had been recommended.

In conclusion, a diverting stoma could decrease the rate of immediate anastomosis-related complications following an ULAR for rectal cancer. However, the overall complication rates associated with diverting stoma were non-negligible. Judicious patient selection and a meticulous surgical technique are recommended when either creating or closing a diverting stoma following an uLAR.

\section{CONFLICT OF INTEREST}

No potential conflict of interest relevant to this article was reported.

\section{REFERENCES}

1. Nakagoe T, Ishikawa H, Sawai T, Tsuji T, Takeshita H, Nanashima A, et al. Oncological outcome of ultra-low anterior resection with total mesorectal excision for carcinoma of the lower third of the rectum: comparison of intrapelvic double-stapled anastomosis and transanal coloanal anastomosis. Hepatogastroenterology 2005;52: 1692-7.

2. Everett WG, Friend PJ, Forty J. Comparison of stapling and hand- suture for left-sided large bowel anastomosis. Br J Surg 1986;73: 345-8.

3. Waxman BP. Large bowel anastomoses. II. The circular staplers. Br J Surg 1983;70:64-7.

4. den Dulk M, Smit M, Peeters KC, Kranenbarg EM, Rutten HJ, Wiggers T, et al. A multivariate analysis of limiting factors for stoma reversal in patients with rectal cancer entered into the total mesorectal excision (TME) trial: a retrospective study. Lancet Oncol 2007;8:297-303.

5. Jung SH, Yu CS, Choi PW, Kim DD, Park IJ, Kim HC, et al. Risk factors and oncologic impact of anastomotic leakage after rectal cancer surgery. Dis Colon Rectum 2008;51:902-8.

6. Mirnezami A, Mirnezami R, Chandrakumaran K, Sasapu K, Sagar P, Finan P. et al. Increased local recurrence and reduced survival from colorectal cancer following anastomotic leak: systematic review and meta-analysis. Ann Surg 2011;253:890-9.

7. Rullier E, Laurent C, Garrelon JL, Michel P, Saric J, Parneix M. Risk factors for anastomotic leakage after resection of rectal cancer. Br J Surg 1998;85:355-8.

8. Karanjia ND, Corder AP, Bearn P, Heald RJ. Leakage from stapled low anastomosis after total mesorectal excision for carcinoma of the rectum. Br J Surg 1994;81:1224-6.

9. Makela JT, Kiviniemi H, Laitinen S. Risk factors for anastomotic leakage after left-sided colorectal resection with rectal anastomosis. Dis Colon Rectum 2003;46:653-60.

10. Kapiteijn E, Marijnen CA, Nagtegaal ID, Putter H, Steup WH, Wiggers T, et al. Preoperative radiotherapy combined with total mesorectal excision for resectable rectal cancer. N Engl J Med 2001;345:638-46.

11. Sauer R, Becker H, Hohenberger W, Rodel C, Wittekind C, Fietkau $\mathrm{R}$, et al. Preoperative versus postoperative chemoradiotherapy for rectal cancer. N Engl J Med 2004;351:1731-40.

12. Mealy K, Burke P, Hyland J. Anterior resection without a defunctioning colostomy: questions of safety. Br J Surg 1992;79:305-7.

13. Karanjia ND, Corder AP, Holdsworth PJ, Heald RJ. Risk of peritonitis and fatal septicaemia and the need to defunction the low anastomosis. Br J Surg 1991;78:196-8.

14. Marusch F, Koch A, Schmidt U, Geibetaler S, Dralle H, Saeger $\mathrm{HD}$, et al. Value of a protective stoma in low anterior resections for rectal cancer. Dis Colon Rectum 2002;45:1164-71.

15. Dehni N, Schlegel RD, Cunningham C, Guiguet M, Tiret E, Parc $\mathrm{R}$. et al. Influence of a defunctioning stoma on leakage rates after low colorectal anastomosis and colonic J pouch-anal anastomosis. Br J Surg 1998;85:1114-7.

16. Matthiessen P, Hallbook O, Rutegard J, Simert G, Sjodahl R. Defunctioning stoma reduces symptomatic anastomotic leakage after low anterior resection of the rectum for cancer: a randomized multicenter trial. Ann Surg 2007;246:207-14.

17. Tan WS, Tang CL, Shi L, Eu KW. Meta-analysis of defunctioning stomas in low anterior resection for rectal cancer. Br J Surg 2009; 96:462-72.

18. Wong NY, Eu KW. A defunctioning ileostomy does not prevent 
clinical anastomotic leak after a low anterior resection: a prospective, comparative study. Dis Colon Rectum 2005;48:2076-9.

19. Matthiessen P, Hallbook O, Andersson M, Rutegard J, Sjodahl R. Risk factors for anastomotic leakage after anterior resection of the rectum. Colorectal Dis 2004;6:462-9.

20. Machado M, Hallbook O, Goldman S, Nystrom PO, Jarhult J, Sjodahl R. Defunctioning stoma in low anterior resection with colonic pouch for rectal cancer: a comparison between two hospitals with a different policy. Dis Colon Rectum 2002;45:940-5.

21. Chow A, Tilney HS, Paraskeva P, Jeyarajah S, Zacharakis E, Purkayastha $S$. The morbidity surrounding reversal of defunctioning ileostomies: a systematic review of 48 studies including 6,107 cases. Int J Colorectal Dis 2009;24:711-23.

22. Kaidar-Person O, Person B, Wexner SD. Complications of construction and closure of temporary loop ileostomy. J Am Coll Surg 2005;201:759-73.

23. Hassan I, Larson DW, Wolff BG, Cima RR, Chua HK, Hahnloser $\mathrm{D}$, et al. Impact of pelvic radiotherapy on morbidity and durability of sphincter preservation after coloanal anastomosis for rectal cancers. Dis Colon Rectum 2008;51:32-7.

24. Enker WE, Merchant N, Cohen AM, Lanouette NM, Swallow C, Guillem J, et al. Safety and efficacy of low anterior resection for rectal cancer: 681 consecutive cases from a specialty service. Ann Surg 1999;230:544-52.

25. Pakkastie TE, Ovaska JT, Pekkala ES, Luukkonen PE, Jarvinen HJ. A randomised study of colostomies in low colorectal anastomoses. Eur J Surg 1997;163:929-33.

26. Law WL, Choi HK, Lee YM, Ho JW, Seto CL. Anastomotic leakage is associated with poor long-term outcome in patients after curative colorectal resection for malignancy. J Gastrointest Surg
2007;11:8-15.

27. McArdle CS, McMillan DC, Hole DJ. Impact of anastomotic leakage on long-term survival of patients undergoing curative resection for colorectal cancer. Br J Surg 2005;92:1150-4.

28. Hallbook O, Sjodahl R. Anastomotic leakage and functional outcome after anterior resection of the rectum. Br J Surg 1996;83:60-2.

29. Nesbakken A, Nygaard K, Lunde OC. Outcome and late functional results after anastomotic leakage following mesorectal excision for rectal cancer. Br J Surg 2001;88:400-4.

30. Lindgren R, Hallbook O, Rutegard J, Sjodahl R, Matthiessen P. What is the risk for a permanent stoma after low anterior resection of the rectum for cancer? A six-year follow-up of a multicenter trial. Dis Colon Rectum 2011;54:41-7.

31. Garcia-Botello SA, Garcia-Armengol J, Garcia-Granero E, Espi A, Juan C, Lopez-Mozos F, et al. A prospective audit of the complications of loop ileostomy construction and takedown. Dig Surg 2004;21:440-6.

32. Winslet MC, Barsoum G, Pringle W, Fox K, Keighley MR. Loop ileostomy after ileal pouch-anal anastomosis: is it necessary? Dis Colon Rectum 1991;34:267-70.

33. Gooszen AW, Geelkerken RH, Hermans J, Lagaay MB, Gooszen HG. Temporary decompression after colorectal surgery: randomized comparison of loop ileostomy and loop colostomy. Br J Surg 1998;85:76-9.

34. Senapati A, Nicholls RJ, Ritchie JK, Tibbs CJ, Hawley PR. Temporary loop ileostomy for restorative proctocolectomy. Br J Surg 1993; 80:628-30.

35. Wexner SD, Taranow DA, Johansen OB, Itzkowitz F, Daniel N, Nogueras JJ, et al. Loop ileostomy is a safe option for fecal diversion. Dis Colon Rectum 1993;36:349-54. 